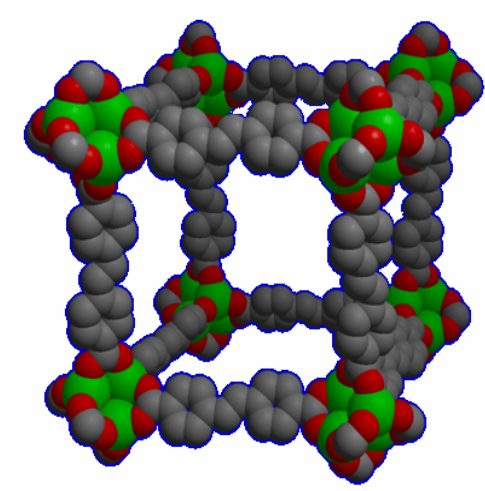

It was shown that optical properties of both $\mathbf{1}$ and $\mathbf{2}$ correlate with the local ligand environments observed in the crystal structures. In both cases, the rigidity of the stilbene linker increases upon coordination to the inorganic units through inhibition of torsion about the central ethylene bond, resulting in luminescent crystals with increased emission lifetimes compared to solutions of trans-stilbene. The emission spectrum of $\mathbf{2}$ is found to depend on the nature of the incorporated solvent molecules, suggesting use of this or related materials in sensor applications.

\section{MS13 P13}

Spin crossover and supramolecular organization of a new family of iron (II) dinuclear complexes Bernard Tinant $^{\mathrm{a}}$, Nicolas De Crom ${ }^{\mathrm{b}}$, Yann Garcia ${ }^{\mathrm{b}}{ }^{\mathrm{a}}$ Unité de chimie structurale et des mécanismes réactionnels. b Unité de chimie des matériaux inorganiques et organiques, Université Catholique de Louvain, Louvainla-Neuve, Belgium. E-mail: tinant@chim.ucl.ac.be

\section{Keywords: Molecular switches; Spin-crossover; Iron} (II) dinuclear complexes

Spin crossover materials are important coordination compounds wherein the spin state can be reversibly switched by external stimuli [1]. A novel family of dinuclear iron(II) compounds with a triple-helicate architecture has been recently synthesized [2] and their spin pairs population studied [3]. In the present work, new iron(II) complexes have been obtained with $\mathrm{L}$ as bisbidentate ligand which could offer more H-bonding possibilities.

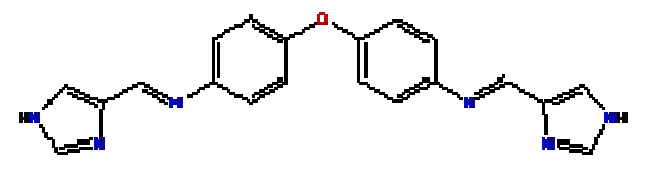

$\mathbf{L}$

By varying the counter-anions and the conditions for crystallization, we obtained suitable single crystals and solved three structures:

$\left[\mathrm{Fe}_{2} \mathrm{~L}_{3}\right]\left(\mathrm{PF}_{6}\right)_{2} \mathrm{Cl}\left(\mathrm{C}_{3} \mathrm{H}_{3} \mathrm{O}_{4}\right) \cdot 5 \mathrm{CH}_{3} \mathrm{OH} \cdot 3 \mathrm{H}_{2} \mathrm{O}$

$\left[\mathrm{Fe}_{2} \mathrm{~L}_{3}\right]\left(\mathrm{C}_{6} \mathrm{H}_{4} \mathrm{BrSO}_{3}\right)_{4} \cdot 7 \mathrm{CH}_{3} \mathrm{OH} \cdot \mathrm{H}_{2} \mathrm{O}$

$\left[\mathrm{Fe}_{2} \mathrm{~L}_{3}\right]\left(\mathrm{PF}_{6}\right)_{3} \mathrm{Cl} \cdot 5 \mathrm{CH}_{3} \mathrm{OH} \cdot 2 \mathrm{H}_{2} \mathrm{O}$

The structure was refined at two temperatures for the third compound. Two iron sites are in the high-spin state at 250 $\mathrm{K}$ and are found in an intermediate state at $120 \mathrm{~K}$ (highspin/low-spin). Complementary ${ }^{57} \mathrm{Fe}$ Mössbauer studies are in progress to shed more light on the spin crossover behaviour of this dinuclear compound. The structures will be presented in details.
[1] Gütlich P., Garcia Y., Goodwin H.A., Chem. Soc. Rev. 2000, $29,419$.

[2] Tuna F., et al., Chem. Eur. J. 2004, 10, 5737

[3] Garcia Y., et al., Eur. J. Inorg. Chem. 2006, 3333.

\section{MS13 P14}

Hydrogen bond in Tri (2-hydroxyanilinium) hexachlorostin (IV) chloride trihydrate. Sofiane Bouacida $^{\mathrm{a}, \mathrm{b} *}$, Hocine Merazig ${ }^{\mathrm{b}}$ and Patricia BenardRocherulle $^{\mathrm{c}}$ a)Dpt de Chimie, Université de Béjaia ,Alegria. b) Lacmom, Université Constantine, Algeria .c) UMR 6226 CNRS, Université de RennesI, France.

E-mail : Bouacida_sofiane@yahoo.fr

Keywords: Hydrogen bond, Single crystal, Hybrid materials.

Organic-inorganic hybrid materials of formula $\left(\mathrm{R}-\mathrm{NH}_{3}\right)$, $\mathrm{SnXn}$, where $\mathrm{X}=\mathrm{F}, \mathrm{Cl}, \mathrm{Br}$ or $\mathrm{I}$, exhibit interesting magnetic, optical and electronic properties [1], [2]. Within our research of hybrid compounds based on tin a new crystal structure has been investigated.

The title compound, $3\left(\mathrm{C}_{6} \mathrm{H}_{8} \mathrm{NO}^{+}\left(\mathrm{SnCl}_{6}\right)^{2-} \mathrm{Cl} \quad .3\left(\mathrm{H}_{2} \mathrm{O}\right)\right.$, crystallized in Monoclinic system, with $\mathrm{P} 2_{1} / \mathrm{n}$ space group.

The crystal structure can be described as double layers of $\left[\mathrm{SnCl}_{6}\right]$ octahedral and 2-hydroxyanilinium cations parallel to (10-1) plane, with the chloride ions and the water molecules sandwiched between the double layers.

In this structure, four types of hydrogen bonds are observed,

viz. cation-cation, cation-anion, cation-water and waterwater,

with the $\mathrm{N}$ and $\mathrm{O}$ atoms of the cation and the water molecules acting as donors and with the $\mathrm{Cl}^{-}$ions and the $\mathrm{O}$ atoms of the water molecules acting as acceptors .

These intermolecular bonds link the molecules within the layers and also link the layers together, delineating a threedimensional network and reinforcing the cohesion of the structure.

[1] Aruta, C., Licci, F. Zappettini, A., Bolzoni, F., Rastelli, F., Ferro, P. \& Besagni, T. (2005). Appl. Phys. A 81, 963-968..

[2] Knutson, J. L. \& Martin J. D. (2005). Inorg. Chem. 44, 46994705 .

\section{MS13 P15}

Synthesis, Characterization and Crystal Structure of a Three-Dimensional Alkaline-Earth Diphenatete Complex: $\left[\mathrm{Ba}\left(\mathrm{H}_{2} \mathrm{O}\right)_{4}\left(\mathrm{OOC}-\left(\mathrm{C}_{6} \mathrm{H}_{4}\right)_{2}-\mathrm{COO}\right)\right] 0.25 \mathrm{H}_{2} \mathrm{O}$

S. Djehni ${ }^{\mathrm{a}}$, F. Balegroune ${ }^{\mathrm{a}}$, A. Guehria-Laidoudi ${ }^{\mathrm{a}}$ ${ }^{a}$ Laboratoire de Cristallographie-Thermodynamique, Faculté de Chimie, USTHB, BP32, El-Alia, Bab-Ezzouar, Alger, Algérie.E-mail: fadilabalegroune@yahoo.fr

Keywords: diphenate, barium compounds, crystal structure analysis

Intense research activity during the last few years employing benzene carboxylic acids such as 2,2'diphenyldicarboxylic acid $\left(\mathrm{H}_{2} \mathrm{dpdc}\right)$ has resulted in many new compounds with fascinating structures. These coordination polymers possess one-, two- and threedimensionally extended structures and are attractive for their diverse coordination modes, intriguing structures, porosity and many potential uses in the areas of catalysis, sorption and luminescence [1-4]. To the best of our 
knowledge, alkaline-earth 2,2'-diphenyldicarboxylate complexes have never been reported.

In this context and following our systematic studies on the alkaline-earth dicarboxylates complexes with 2,2'diphenyldicarboxylic acid, a new barium(II) compound of formula $\left[\mathrm{Ba}\left(\mathrm{H}_{2} \mathrm{O}\right)_{4}(\mathrm{dpdc})\right] 0.25 \mathrm{H}_{2} \mathrm{O}$ has been prepared and structurally characterized by $\mathrm{X}$-ray crystallography.

The Barium (II) ions are nine coordinated by three oxygen atoms from two diphenato groups and six oxygen atoms from six water molecules of which five acting as bridging ligands and one as monodentate. The distances $\mathrm{Ba}-\mathrm{O}$ range from 2.704(5) to 2.974(4) $\AA$ forming a slightly distorted monocapped dodecahedron. The structure of $\left[\mathrm{Ba}\left(\mathrm{H}_{2} \mathrm{O}\right)_{4}(\mathrm{dpdc})\right]_{n}$ consists of two-dimensional layers, built up from the self-assembly of zigzag chains of face and edge-sharing $\left\{\mathrm{BaO}_{9}\right\}$ polyhedra linked by bridging bidendate diphenate anions through different coordination modes of the carboxylate groups. The $\mathrm{Ba}$... Ba distances across these chains are 4.3519(6) and 4.6013(5) $\AA$. The polymer layers form a three-dimensional network via $\mathrm{O}$ $\mathrm{H}$. . O hydrogen-bond interactions between the coordinated water molecules and the $\mathrm{O}$ atoms of the carboxylate groups.

[1] J .M. Rueff, S. Pillet, N. Claiser, G. Bonaventure, M. Souhassou, P. Rabu, Eur. J. Inorg. Chem., 2002, 895.

[2] H. Kumagai, K. Inoue, M. Kurmoo, Bull. Chem. Soc. Jpn., $75,2002,1283$.

[3] A. Thirumurugan, S. K .Pati, M. A. Green, S. Natarajan, J. Mater. Chem., 13, 2003, 2937.

[4]Y.B. Wang, X.J. Zheng, W. J. Zhuang, L. P. Jin, Eur. J. Inorg. Chem., 2003, 1355.

\section{MS13 P16}

Gas sorption and binding in a nonporous single crystal Tia Jacobs, Gareth O. Lloyd, Liliana Dobrzańska, Martin W. Bredenkamp and Leonard J. Barbour, Department of Chemistry, University of Stellenbosch, South Africa.

E-mail: tj@sun.ac.za.

\section{Keywords: gas-solid interactions; discrete metallocycles; single crystal diffraction}

Recently, coordination chemistry has become an active area of research in the field of crystal engineering of porosity. The coordination-driven motif offers an easier alternative to the synthesis of discrete supramolecular units when considering the classic syntheses involved in producing covalently bonded macromolecules. ${ }^{[1]}$ Despite efforts to predict and define the parameters governing the assembly of discrete coordination compound architectures $^{[2]}$, rational design of these types of molecular structures is still not possible. We are interested in molecules with this topology because, even if efficiently close-packed in the crystalline state, these structural synthons, can yield significant solvated space in the crystal. ${ }^{[3]}$ Here we report an imidazole-derived bridging ligand self-assembling with metal ions to form a series of discrete neutral metallocycles. In these solvent templated systems it is possible to remove guest solvent molecules without concomitant rearrangement of the host lattice. Such structures possess cavities of ca. $110 \AA^{3}$ and have the notable feature of being structurally flexible during the gas sorption process. Since the desolvation procedure and subsequent gas sorption experiments can all occur as single-crystal to single-crystal transformations, it has been possible to study the gas-solid interactions using X-ray diffraction techniques. These studies are also complemented by gravimetric and volumetric gas sorption experiments.

[1] S. Leiniger, B. Olenyuk and P.J. Stang, Chem. Rev. 100, 853 (2000).

[2] B. Moulton and M.J. Zaworotko, Chem. Rev. 101, 1629 (2001).

[3] L. Dobrzańska, G.O. Lloyd, H.G. Raubenheimer and L.J. Barbour, J. Am. Chem. Soc. 127, 13134 (2005).

\section{MS13 P17}

Crystal Structure of 3,4,4-Trichloro-2-nitro-1propylsulfanyl-1-(4-thiomorpholinly)buta-1,3-diene

N.Gulsah Deniz ${ }^{\mathrm{a}}$, Cemil Ibis, ${ }^{\mathrm{a}}$ Department of Chemistry, Istanbul University. Istanbul, Turkey.

E-mail: yurdakul@istanbul.edu.tr

Keywords: organic sulfur compounds, chemical crystallography, biologically important compounds.

Thiomorpholine analogues have found applications in medicine and agriculture [1]. Subsituted thiomorpholino, morpholino and piperidino compounds enhanced the activity against Gram-positive bacteria, but reduced the activity against Gram-negative bacteria [2]. The aim of this study was to determine the conformation of the title compound [3]. In the title compound, $\mathrm{C}_{11} \mathrm{H}_{15} \mathrm{Cl}_{3} \mathrm{~N}_{2} \mathrm{O}_{2} \mathrm{~S}_{2}$, the structure contains the expected N,S-substituted butadienyl skeleton, an alkylsulfanyl chain and a thiomorpholine ring. The thiomorpholine ring adopts a chair conformation and the butadiene has a conformation closer to cisoid than to transoid. The $\mathrm{C}-\mathrm{C}$ bond lengths within the butadiene unit are similar to those in related compounds [4]. The thiomorpholine ring adopts a chair conformation, as shown by the puckering angles of $\varphi=$ $1(3)^{0}$ and $\theta=10.2(4)^{0}[5]$.

[1] Barbacyn, M. R., Hutchinson, D. K., Brickner, S. J., Cynamon, M. H., Kilburn, J. O., Klemens, S. P., Glickman, S. E., Grega, K. C., Hendges, S. K., Toops, D. S., Ford, C. W. \& Zurenko, G. E. J. Med. Chem, 1996, 6802.

[2] Taguchi, M., Kondo, H., Inoue, Y., Kawahata, Y., Jinbo, Y., Sakamoto, F. \& Tsukamoto, G. J. Med. Chem, 1992, 35, 94.

[3] Ibis, C., Deniz, N.G., Acta. Cyrst, 2006, E62, 05373.

[4] Ibis, C, Deniz, N.G, Acta. Cyrst, 2007, E63, o1091.

[5] Cremer, D., Pople, J. A. , J. Am. Chem. Soc, 1975, 97, 1354.

\section{MS13 P18}

Metal-Organic Frameworks using pyridyldiyne ligands Leigh Loots, Martin W. Bredenkamp and Leonard J. Barbour, Department of Chemistry, University of Stellenbosch.E-mail: leighl@sun.ac.za

Keywords: metal-organic frameworks, gas sorption, porosity

The ability to predict and thus control the assembly of networks is an ongoing challenge. It has been proposed that thin, rigid ligands will behave in a more predictable manner, than other, more flexible versions. The assembly of molecular frameworks and network polymers using bidentate ligands such as 4,4'-bipyridyldiynes has been of considerable interest. Their rod-like structures, owing to the alkynyl spacers as well as their conjugated systems that are of a rigid nature, are of specific interest. ${ }^{0} 4,4^{\prime}-$ Bipyridine has previously been used to assemble a variety of crystalline designs such as chains, ladders, squares, diamondoids, etc. as well as a few innovative coordination polymer networks exhibiting a measure of porosity. ${ }^{0}$ In 